\title{
Gütesiegel Buchkindergarten: 56 Einrichtungen für herausragende Leseförderung ausgezeichnet
}

\section{Gütesiegel für frühkindliche Leseförderung / 56 Kindergärten in ganz Deutschland aus 251 Bewerbungen ausgewählt / Kinderbuchautor Paul Maar gratuliert mit Gedicht}

https://doi.org/10.1515/bd-2022-0005

Für ihren herausragenden Einsatz im Bereich der frühkindlichen Leseförderung wurden 56 Kindertagesstätten mit dem Gütesiegel Buchkindergarten geehrt. Alle ausgezeichneten Einrichtungen sind unter www.guetesiegel-buchkindergarten. de/preisvergabe-2021/preistraeger-2021.html abrufbar.

Durch Angebote wie die monatliche Vorstellung eines „Buchs des Monats“, den Bibliotheksführerschein für Kindergartenkinder oder Online-Lesenächte vermitteln sie auf spielerische Weise den Umgang mit Büchern. Auch regelmäßige Vorlesezeiten und Aktionen, die die Geschichten der Bücher in den Kindergartenalltag überführen, sind zentraler Bestandteil dieses Engagements. 251 Kindergärten aus ganz Deutschland hatten sich für das Gütesiegel beworben.

Mit dem Gütesiegel Buchkindergarten zeichnen der Börsenverein des Deutschen Buchhandels und der Deutsche Bibliotheksverband e.V. (dbv) Kindergärten aus, in denen ein besonderer Fokus auf frühkindlicher Leseförderung liegt. Buchkindergärten führen mit kreativen Aktionen rund ums Lesen, Erzählen und Reimen an das Medium Buch heran. Der enge Austausch mit Buchhandlungen und Bibliotheken spielen hierbei eine wichtige Rolle. Das Gütesiegel ist für drei Jahre gültig.

\section{Fachjury}

Über die Vergabe des Gütesiegels Buchkindergarten entschied eine Fachjury. Die Mitglieder sind: Jutta Bummel (Buchhandlung Eulenspiegel, Hochheim), Meike Betzold (Stadt- und Schulbibliothek, Kelsterbach), Sara Dencescu (Evangelischer Kindergarten Friedensgemeinde, Kelsterbach), Tanja Eger (Buchhandlung Mäx + Moritz, Baden-Baden), Antje Ehmann (Fachjournalistin und Autorin), Christine Hauke-Dreesen (Erzieherin, Buchhändlerin und Literaturpädagogin), Heike Holland (Referentin für Tagesangebote für Kinder, Der Paritätische NRW) und Dr. Stephanie Jentgens (Universität Halle-Wittenberg). 


\section{Gedicht von Schirmherr Paul Maar zur Auszeichnung 2021}

Der Kinderbuchautor und Illustrator Paul Maar ist Schirmherr des Gütesiegels Buchkindergarten. Er gratuliert mit einem Gedicht zur diesjährigen Vergabe: https://www.guetesiegel-buchkindergarten.de/das-guetesiegel/schirmherr.html.

Das Gütesiegel Buchkindergarten wird 2021 zum dritten Mal verliehen. Förderer sind die Verlagsgruppe Beltz, der Carlsen Verlag, die Buchhandlung Eulenspiegel (Hochheim am Main), der Moritz Verlag, die Verlagsgruppe Oetinger, die Taunus Sparkasse und Thienemann-Esslinger. Die Interessengruppe Leseförderung des Börsenvereins initiierte das Gütesiegel. Weitere Informationen sind unter www.guetesiegel-buchkindergarten.de zu finden.

\section{Kontakte für die Medien}

Kristin Bäßler

Deutscher Bibliotheksverband

Leitung Kommunikation / Pressesprecherin

Tel.: + 49 (0)30 6449899 25 | E-Mail: baessler@bibliotheksverband.de

Thomas Koch

Börsenverein des Deutschen Buchhandels e.V.

Leiter Presse- und Öffentlichkeitsarbeit

Tel.: +49 (0) 69 1306-293 | E-Mail: t.koch@boev.de

Marie Böhlke

Junior-PR-Managerin

Tel.: +49 (0) 69 1306-292 | E-Mail: boehlke@boev.de 